\title{
Comparison of 2D debris-flow simulation models with field events
}

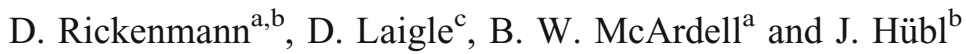 \\ ${ }^{a}$ Division of Natural Hazards, Swiss Federal Research Institute WSL, Birmensdorf, Switzerland \\ ${ }^{b}$ Department Civil Engineering and Natural Hazards, Institute of Mountain Risk Engineering, University \\ of Natural Resources and Applied Life Sciences, Peter Jordan-Strasse 82, A-1190 Vienna, Austria \\ E-mail: dieter.rickenmann@boku.ac.at \\ ${ }^{c}$ Cemagref, Snow Avalanche and Torrent Control Research Unit, Saint-Martin-d'Hères, France
}

Received 5 November 2004; accepted 4 August 2005

\begin{abstract}
Three two-dimensional (2D) debris-flow simulation models are applied to two large welldocumented debris-flow events which caused major deposition of solid material on the fan. The models are based on a Voellmy fluid rheology reflecting turbulent-like and basal frictional stresses, a quadratic rheologic formulation including Bingham, collisional and turbulent stresses, and a Herschel-Bulkley rheology representing a viscoplastic fluid. The rheologic or friction parameters of the models are either assumed a priori or adjusted to best match field observations. All three models are capable of reasonably reproducing the depositional pattern on the alluvial fan after the models have been calibrated using historical data from the torrent. Accurate representation of the channel and fan topography is especially important to achieve a good replication of the observed deposition pattern.
\end{abstract}

Keywords: debris flow, field observation, friction law, rheologic parameter, simulation model

\section{Introduction}

Due to the complexity of the debris flow process, a number of models were developed to simulate the flow behaviour. In applications to real debris flows, singlephase models are often used. This represents a simplification of a debris flow where the main constituents are water and solid material consisting of a wide range of grain sizes. Because the flow process is still poorly understood and the limits between different constitutive approaches can hardly be assessed for real mixtures, the application of simplified models such as single-phase models appears to be a reasonable first step towards a systematic application and evaluation of simulation 
models. In this way, the number of model parameters, which are usually not well constrained, remains restricted.

Application of computational debris flow models to field examples necessitates many assumptions about the details of the event and pre-event topography. Similarly, the debris flow process remains incompletely understood and approximations - many of which have not been thoroughly evaluated - should also be considered when using debris flow models for engineering practice. In principle it is possible to first test such models in the laboratory with, for example, clay-water mixtures [25]. However, for more realistic materials including coarse particles, the scaling effects are still difficult to account for. Debris flow routing models are necessary for engineering practice and some models have been in regular use for a number of years, e.g., for producing hazard maps or for evaluating the effectiveness of mitigation structures. Therefore we believe that systematic comparisons of debris flow models with well-documented field cases is of value.

For hazard mapping and risk assessment, "larger" debris-flow events (a few $1,000 \mathrm{~m}^{3}$ to a few $100,000 \mathrm{~m}^{3}$ ) are especially interesting because the water-sediment mixture often leaves the channel on the fan, potentially damaging inhabited areas or infrastructure. The objective of this study is to evaluate the suitability of twodimensional (2D) numerical simulation models to replicate observed deposition patterns of "larger" debris flows on fans. Three models are applied to two different field cases. The DFEM (Debris flow Finite Element Model), developed by the Swiss Federal Research Institute WSL, is a simulation model including a number of friction relations or "rheologic" approaches to account for the debris flow characteristics [31]. Here, a 2D version of the model with a Voellmy fluid friction law is used. The FLO$2 \mathrm{D}^{\circledR}$ model, a commercial code in widespread practical use, is a finite difference debris and mud flow simulation program based on a quadratic rheologic law [34]. The 2D model developed by Cemagref in Grenoble is a finite volume model including the Herschel-Bulkley (HB) rheology representing a viscoplastic fluid [25]. This rheologic model was found to be generally valid for muddy-type debris flow material with sufficient clay content [5]. The three models cover different friction relationships which represent turbulent, frictional, collisional, and laminar approaches to describe the energy losses.

It is often possible with the models to vary other coefficients (e.g., sediment concentration); however, such second-order adjustments were not made here, because the main goal is to compare the overall suitability of the rheological models for simulation of deposition on the fan.

\section{Numerical simulation models for debris flows}

Many numerical simulation models for debris flows assume that the solid-fluid mixture behaves as a quasi-homogeneous fluid. A number of models are based on a rheologic formulation for a Bingham fluid or the more generalized Herschel-Bulkley 
representation for a viscoplastic fluid [5,10,19,25,26,49]. Some models include an additional friction term accounting for channel roughness and turbulence [13,22,34]. Independent rheologic measurements were available only in a limited number of applications of such models to field cases (e.g., [29]). Often, appropriate values for the rheologic parameters were assumed or estimated from field observations.

Single-phase models, which include the option of selecting more than one rheological law, are relatively uncommon (e.g., [16,17,31,39]). In comparisons of rheological laws, the Voellmy rheology has proven to be useful for describing debris flows in one dimension $[1,18,31,39]$. This relation has also been successfully applied to interpreting the runout distance of landslides [3] and rockfalls [7].

The fluid and sediment phases are treated separately in several models based on inertial grain flow concepts (e.g., $[2,32,33,45,47,48]$ ) and generally leave the phases uncoupled. Another approach is based on the Savage and Hutter [44] equations, which have been generalized to account for mixtures (e.g., [8,20,21]). These models are generally not yet available for engineering practice and are not included herein.

It is often possible to obtain reasonable model results for some characteristics of natural debris flows [42]. Often only the deposition pattern is fairly accurately known, possibly supplemented by the rheologic analysis of material samples. In other cases, there is also limited information of flow velocities and depths. However, most existing models have not been thoroughly tested with actual field cases. This lack of testing may be partly due to scarce data on observed debris-flow parameters, and due to the fact that no simple methods are available to directly determine the rheologic or model input parameters.

No simple model appears to be capable of correctly reproducing different features of debris flow behavior [20]. A complicating factor is the large variability of material composition and water content. In addition to the general difficulty of measuring relevant flow and material parameters, the material properties may change within the wave, typically with large boulders at the front and a more fluid mixture towards the tail. Furthermore, the flow parameters can also change along the flow path. Another major difficulty is distinguishing between appropriate flow regimes, which may also change along the flow path, and suitable modelling approaches.

\section{Applied simulation models}

All three models discussed below solve the continuity and momentum equations in both orthogonal flow directions. Only the main features are summarized here, and the appropriate literature is cited for each model below. The debris-flow mixture is assumed to be a continuous, homogeneous, and incompressible fluid. The snout and its influence on the flow are neglected. This assumption seems realistic under conditions of wide spreading considered in this study, because in that case, the snout usually splits up or stops early in a confined area of the spreading zone and does not substantially contribute to the formation of levees. Normal stresses are supposed to 
reduce to the expression of the pressure head whose distribution is assumed to be hydrostatic. The effect of shear stresses is supposed to reduce to the bed resistance force. The wall-shear stress at a specific point is assumed identical to its value in steady regime with the same flow height and velocity. The erosive power of the spreading debris-flow is neglected; erosion is likely to be limited in the deposition zone. More dilute flows may occur, for example, after the passage of the main surge; in this case channel incision is expected to be negligible as long as the sediment supply exceeds the sediment transport capacity at the alluvial fan apex. In all models an input hydrograph of the flow can be defined at the upstream boundary.

\subsection{DFEM model}

The DFEM model is based on a finite element solution of the conservative form of the shallow water equations. The frictional resistance term typically used for open channel flow (e.g., a Chézy flow resistance law) is replaced with flow laws which have been proposed to describe debris flow behavior. Both 1D and 2D versions of the DFEM model were developed at the Swiss Federal Research Institute WSL. The numerical model is based on the Finite Element Method TOOLbox (FEMTOOL) libraries developed at the Swiss Federal Institute of Technology, Laboratory of Hydraulics, Hydrology and Glaciology, by Rutschmann [43]. The main modifications for application to debris flow routing are the inclusion of debris flow laws and a treatment of the transition from wet-to-dry cells involving simple cutoff velocities and depths. When the predicted velocity or depth is below some small user-specified value (a few $\mathrm{cm}$ for the flow depth and a few $\mathrm{cm} / \mathrm{s}$ for the velocity), the bed is assumed to be dry. An upwind scheme is used to increase the numerical stability (e.g., [24]). With the 2D model the equations are solved on a mesh composed of triangles of arbitrary geometry (irregularly shaped triangular elements), allowing the mesh to accurately represent complex channel geometries with a minimum number of elements.

The DFEM 1D model solves the shallow water equations in the downstream direction, with flow depth and the unit width discharge as the primary unknowns. The DFEM 2D model solves the equations in both the downstream and cross-stream directions with an additional primary unknown, the cross-stream unit discharge. The continuity and momentum equations are written in the conservative form:

$$
\begin{gathered}
\frac{\partial h}{\partial t}+\frac{\partial q}{\partial x}+\frac{\partial r}{\partial y}=0 \\
\frac{\partial q}{\partial t}+\frac{\partial}{\partial x}\left(\frac{q^{2}}{h}\right)+\frac{\partial}{\partial y}\left(\frac{q r}{h}\right)+\frac{g}{2} \frac{\partial}{\partial x}\left(h^{2}\right)=g h\left(-\frac{\partial z_{b}}{\partial x}-\operatorname{sgn}\left(V_{x}\right) S_{f x}\right) \\
\frac{\partial r}{\partial t}+\frac{\partial}{\partial x}\left(\frac{q r}{h}\right)+\frac{\partial}{\partial y}\left(\frac{r^{2}}{h}\right)+\frac{g}{2} \frac{\partial}{\partial y}\left(h^{2}\right)=g h\left(-\frac{\partial z_{b}}{\partial y}-\operatorname{sgn}\left(V_{y}\right) S_{f y}\right)
\end{gathered}
$$


where $h$ is the flow depth; $q$ and $r$ are the specific discharges per unit width in $x$ - and $y$ directions, respectively; $g$ is the gravitational acceleration; $z_{\mathrm{b}}$ the vertical bottom coordinate of the channel bed; $V_{x}$ and $V_{y}$ are the depth-averaged velocity components in the $x$ - and $y$-directions, respectively; and $S_{f x}$ and $S_{f y}$ are the friction slopes in the $x$ - and $y$-directions, respectively. The sgn (signum) operator is used to ensure that the friction component is correctly accounted for on flow on adverse slopes. For comparison with the equations for the other models below, the discharges $q$ and $r$ can also be expressed in terms of flow depth $h$ and velocities $V_{x}$ and $V_{y}$ as $q=h V_{x}$ and $r=h V_{y}$ for the $x$ - and $y$-directions, respectively.

For the simulations in this study, the Voellmy fluid friction relation was selected:

$$
S_{f x}=\frac{q \sqrt{q^{2}}}{h^{3} C^{2}}+\cos \alpha \tan \delta
$$

where $q$ is the specific discharge per unit width in the $x$-direction, $C$ is a pseudo-Chézy coefficient, $\alpha$ is the bottom slope angle and $\delta$ is the Coulomb or basal friction angle. This equation, shown here for the $x$-direction, is used in both flow directions. The first term on the right-hand side accounts for friction losses proportional to the velocity squared, as in turbulent water flows, and the second term reflects frictional losses which are assumed to be concentrated in a narrow shear layer close to the bed [1]. The DFEM-1D model with the Voellmy rheology was successfully applied to a real debris flow event in a Swiss torrent where accurate measurements of flow parameters are available [30]. Common to approaches with additive friction terms is the assumption that each stress or friction component acts independently of the presence of others [28].

Other combinations of friction laws can be selected in the DFEM model (e.g., Bingham, dilatant, turbulent and Coulomb; [31]) but they were not applied in this study. In the DFEM model, the magnitude of the friction term (expressed in units of energy) is not allowed to exceed the local kinetic energy of the flow, in order to enhance numerical stability.

\subsection{FLO-2D model}

The water flood and mud flow simulation program FLO-2D ${ }^{\circledR}$ was developed by O'Brien et al. [34]. The governing equations [9] include the continuity equation

$$
\frac{\partial h}{\partial t}+\frac{\partial h V_{x}}{\partial x}+\frac{\partial h V_{y}}{\partial y}=i
$$

and the two-dimensional equations of motion:

$$
S_{f x}=S_{o x}-\frac{\partial h}{\partial x}-\frac{V_{x}}{g} \frac{\partial V_{x}}{\partial x}-\frac{V_{y}}{g} \frac{\partial V_{x}}{\partial y}-\frac{1}{g} \frac{\partial V_{x}}{\partial t}
$$




$$
S_{f y}=S_{o y}-\frac{\partial h}{\partial y}-\frac{V_{y}}{g} \frac{\partial V_{y}}{\partial y}-\frac{V_{x}}{g} \frac{\partial V_{y}}{\partial x}-\frac{1}{g} \frac{\partial V_{y}}{\partial t}
$$

where $h$ is the flow depth and $V_{x}$ and $V_{y}$ are as defined above. The excess rainfall intensity $i$ may be nonzero on the flow surface; however, it has been set to zero in our applications. The friction slope components $S_{f x}$ and $S_{f y}$ are written as function of bed slope $S_{\mathrm{ox}}$ and $S_{\mathrm{oy}}$, pressure gradient and convective and local acceleration terms [9].

The basic equation for the total friction slope $S_{f}$ considers a combination of yield, viscous, collision and turbulent stress components. Based on the so-called quadratic rheologic model of Julien and Lan [23], the total friction slope $S_{f}$ is expressed as:

$$
S_{f}=\frac{\tau_{\mathrm{B}}}{\rho g h}+\frac{K_{l} \mu_{\mathrm{B}} V}{8 \rho g h^{2}}+\frac{n^{2} V^{2}}{h^{4 / 3}}
$$

where $\tau_{\mathrm{B}}$ is the Bingham yield stress, $\rho$ is mixture density, $g$ is gravitational acceleration, $\mu_{\mathrm{B}}$ is the Bingham viscosity, $V$ is the mean flow velocity, $K_{1}$ is the laminar flow resistance coefficient, and $n$ is the pseudo-Manning's resistance coefficient which accounts for both turbulent boundary friction and internal collisional stresses. The laminar flow resistance coefficient $K_{1}$ equals 24 for smooth, wide, rectangular channels, but is supposed to increase with roughness and irregular crosssection geometry [9]. The Bingham parameters $\tau_{\mathrm{B}}$ and $\mu_{\mathrm{B}}$ are defined as exponential functions of sediment concentration which may vary over time. The resistance coefficient $n$ accounts for both for collisional (inertial grain shear) and turbulent frictional losses. The friction slope is determined separately for both orthogonal flow directions. The FLO-2D ${ }^{\circledR}$ simulation code solves the equations using a finite difference method on a fixed rectangular grid.

The FLO-2D ${ }^{\circledR}$ model has possibly been most widely applied to natural debris flows or compared with other models (e.g., [4,11,12,14]). In some of these applications, the Bingham model parameters were inferred from the measured rheology of samples of the fine material slurry. However, the sediment concentration in the real debris flows and the rheology of the complete mixture are generally not known, and assumptions have to be likewise made regarding the pseudo-Manning coefficient $n$.

\subsection{HB model}

The model used here $[25,27]$ considers one phase for the computation of the unconfined free-surface spreading of viscoplastic materials with a Herschel-Bulkley (HB) rheology. It is based on the conservative form of the steep-slope shallow water equations which are solved using a finite volume technique on a rectangular grid. A 
hydrograph can be specified as boundary condition. The continuity equation and the momentum equations, respectively, are:

$$
\begin{aligned}
& \frac{\partial \boldsymbol{h}}{\partial \boldsymbol{t}}+\frac{\partial\left(\boldsymbol{h} \boldsymbol{V}_{\boldsymbol{x}}\right)}{\partial \boldsymbol{x}}+\frac{\partial\left(\boldsymbol{h} \boldsymbol{V}_{\boldsymbol{y}}\right)}{\partial \boldsymbol{y}}=\mathbf{0} \\
& \frac{\partial\left(\boldsymbol{h} \boldsymbol{V}_{\boldsymbol{x}}\right)}{\partial \boldsymbol{t}}+\frac{\partial\left[\boldsymbol{h} \delta_{1} \boldsymbol{V}_{\boldsymbol{x}}^{2}+\frac{\boldsymbol{g} \boldsymbol{h}^{2} \cos \left(\theta_{x y}\right)}{2}\right]}{\partial \boldsymbol{x}}+\frac{\partial\left(\boldsymbol{h} \delta_{2} \boldsymbol{V}_{\boldsymbol{x}} \boldsymbol{V}_{\boldsymbol{y}}\right)}{\partial \boldsymbol{y}}=\boldsymbol{g h} \sin \left(\theta_{x}\right)-\frac{\boldsymbol{V}_{\boldsymbol{x}}}{\sqrt{\boldsymbol{V}_{\boldsymbol{x}}^{2}+\boldsymbol{V}_{\boldsymbol{y}}^{2}}} \frac{\tau_{\boldsymbol{p}}}{\rho} \\
& \frac{\partial\left(\boldsymbol{h} \boldsymbol{V}_{\boldsymbol{y}}\right)}{\partial \boldsymbol{t}}+\frac{\partial\left(\boldsymbol{h} \delta_{2} \boldsymbol{V}_{\boldsymbol{x}} \boldsymbol{V}_{\boldsymbol{y}}\right)}{\partial \boldsymbol{x}}+\frac{\partial\left[\boldsymbol{h} \delta_{1} \boldsymbol{V}_{\boldsymbol{y}}^{2}+\frac{\boldsymbol{g} \boldsymbol{h}^{2} \cos \left(\theta_{\boldsymbol{x} \boldsymbol{y}}\right)}{2}\right]}{\partial \boldsymbol{y}}=\boldsymbol{g} \boldsymbol{h} \sin \left(\theta_{y}\right)-\frac{\boldsymbol{V}_{\boldsymbol{y}}}{\sqrt{\boldsymbol{V}_{\boldsymbol{x}}^{2}+\boldsymbol{V}_{\boldsymbol{y}}^{2}}} \frac{\tau_{\boldsymbol{p}}}{\rho}
\end{aligned}
$$

where $\theta_{x}$ and $\theta_{y}$ are the slope angles, $\theta_{x y}$ is the steepest slope angle, and $\delta_{1}$ and $\delta_{2}$ are the quadratic correcting coefficients taking into account the shape of the velocity profile.

The friction losses for a laminar flow of a Herschel-Bulkley fluid are given by the following wall shear stress expression for infinitely wide flow [5]:

$$
\tau_{0}=\tau_{c}\left[1+1.93\left[\frac{\tau_{c}}{K}\left(\frac{h}{\sqrt{V_{x}^{2}+V_{y}^{2}}}\right)^{1 / 3}\right]^{-0.9}\right]
$$

where $\tau_{0}$ is the basal shear stress, $\boldsymbol{V}_{\boldsymbol{x}}$ and $\boldsymbol{V}_{\boldsymbol{y}}$ are the components of the (mean) velocity along two perpendicular directions, $\tau_{\mathrm{c}}$ is the yield stress, and $K$ is the viscosity of the material. The shear stress is written here in the vector direction, but decomposed into the orthogonal components for the computation.

The Herschel-Bulkley model is valid only for materials where the fine fraction is large enough to lubricate contacts between grains. According to Coussot [5], a clay fraction (particle size less than $40 \mu \mathrm{m}$ ) greater than $10 \%$ is necessary so that debris flow material may be assumed to behave like a Herschel-Bulkley fluid. 


\section{Application to a debris-flow event in the Varunasch torrent}

The Varunasch catchment is located in the Canton of Grisons in Switzerland. The catchment area is $6.5 \mathrm{~km}^{2}$ above the fan apex, the altitude ranges from 3,453 to $1,040 \mathrm{~m}$ a.s.l., the mean gradient of the torrent is $37 \%$, and the mean gradient of the fan is $15 \%$. The geology is characterized by gneiss, schist and graphite-phyllite, and there are talus scree and surficial moraine deposits. On the fan, a relatively small channel with check dams existed prior to the event; there are also a few houses, a railway track and roads. The debris-flow event occurred on 18 July 1987 and mobilized about $215,000 \mathrm{~m}^{3}$ comprising three main surges and about 10 secondary surges [41]. For the modelling work herein, the discharge at the fan apex was assumed to have a simple symmetrical triangular form with a maximum discharge of $600 \mathrm{~m}^{3} / \mathrm{s}$, based on estimates of front velocity from eyewitnesses and flow cross-section areas from field observations, for a total duration of $720 \mathrm{~s}$, corresponding to a volume of $216,000 \mathrm{~m}^{3}$.

Depths of debris-flow deposits on the fan were estimated using photogrammetry. The majority of the material was deposited on the fan, in the pre-existing channel, and along a small part the river in the main valley at the downstream end of the fan (see also figures 1-3). Near and above the pre-existing channel, deposit thicknesses vary from 2 to $5 \mathrm{~m}$ with a trend for somewhat thicker deposits further downstream. Deposits adjacent to the channel are quite uniform with thicknesses in the order of 1 to $2 \mathrm{~m}$. At the upstream end of the fan, near the fan apex on the northeastern flank, one particular lobe of material, up to $5 \mathrm{~m}$ thick, was deposited along an abandoned channel. At the downstream end of the fan, at the Poschiavino River, the highest deposit thicknesses were observed. A deposit up to $10 \mathrm{~m}$ thick occurred on the right side of the Varunasch torrent channel, in the southernmost corner of the affected area.

The digital elevation model (DEM) is based on 1:2,500 maps for pre- and postevent topography derived from photogrammetric analyses. For the model applications described below, a 5-m quadratic grid topographic model of the fan is used; this grid has a well-delineated channel.

\subsection{Simulations with $H B$ model}

Before running the model, the range of rheologic parameters for use as input to the model was constrained using field observations because no direct measurements of the rheologic parameters are available. Consequently, the validity of the Herschel-Bulkley model could not be supported with laboratory tests on field samples. Using an average thickness of deposits and the mean gradient of the torrential fan, the $\tau_{\mathrm{c}} / \rho$ ratio (equation (3)) was estimated to range from 1.45 to $2.2 \mathrm{~m}^{2} \mathrm{~s}^{-2}$, and a mean value of $1.8 \mathrm{~m}^{2} \mathrm{~s}^{-2}$ is used in the initial simulation. The $K / \tau_{\mathrm{c}}$ ratio $=0.3 \mathrm{~s}^{1 / 3}$ is used for all simulations; this ratio represents a mean value proposed by Coussot et al. [6] on the basis of previous field investigations. 

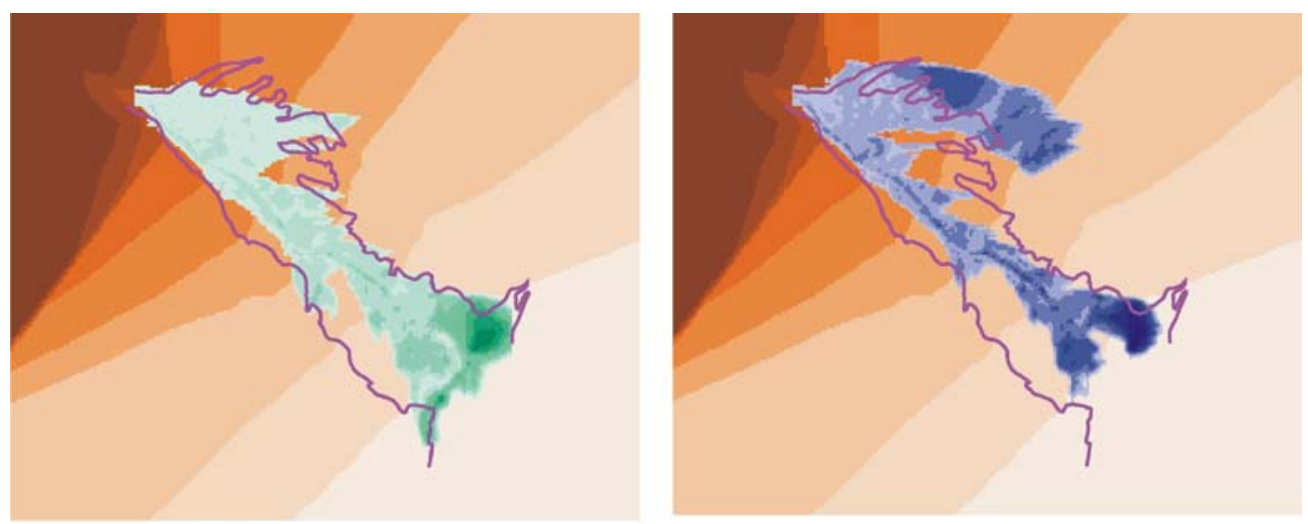

(a)

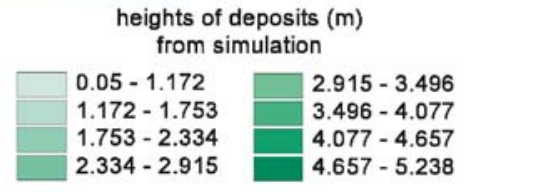

real spreading extent

0

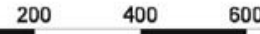

800
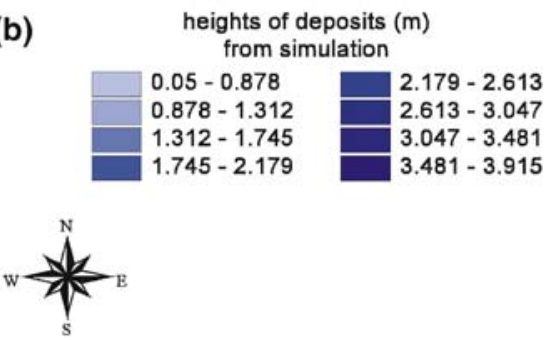

Figure 1. Simulated deposition depths of the Varunasch debris-flow event with the HB model. The simulations are based on: peak discharge $Q_{\mathrm{p}}=600 \mathrm{~m}^{3} \mathrm{~s}^{-1}$ (a) and $Q_{\mathrm{p}}=900 \mathrm{~m}^{3} \mathrm{~s}^{-1}$ (b), event volume $V=$ $216,000 \mathrm{~m}^{3}$, Herschel-Bulkely parameters $\tau_{\mathrm{c}} / \rho=1.8 \mathrm{~m}^{2} \mathrm{~s}^{-2}$ and $K / \tau_{\mathrm{c}}=0.3 \mathrm{~s}^{1 / 3}$. The (purple) outline encompasses the boundary of the observed debris flow deposits.

As a first approximation, crude estimates of the rheologic parameters produce reasonable results for the overall deposition pattern (figure 1a). Modelled overbank deposit thicknesses are less than $2 \mathrm{~m}$ in most areas, in general agreement with observed values. While the easternmost deposit thickness (at the downstream end of the fan) is in reasonable agreement with field observations, the model underpredicts deposition heights in the area with maximum observed thicknesses of up to $10 \mathrm{~m}$ at the southernmost corner of the grid. Another zone not adequately modelled is the southwestern part of the observed deposits where no model deposits were simulated at the right side of the channel. At the northeast corner of the fan, near the fan apex, the complex multi-lobed depositional pattern is only roughly simulated. In general, the simulated lateral spreading is somewhat smaller than in reality.

The independent assessment of rheologic parameters values corresponding to the flowing material is difficult. According to the investigation performed within this study, the sensitivity of the HB model results to variations in the $\tau_{\mathrm{c}} / \rho$ ratio is much higher than the sensitivity to variations of the $K / \tau_{\mathrm{c}}$ ratio. For example, the covered area seems to be more controlled by $\tau_{\mathrm{c}} / \rho$ than by $K / \tau_{\mathrm{c}}$. If $\tau_{\mathrm{c}} / \rho$ is increased by $22 \%$, the surface area of the deposits is reduced by $12 \%$ (table 1 ). A relative variation of $33 \%$ on the $K / \tau_{\mathrm{c}}$ value leads to a change of only $2.5 \%$ in the surface area of the deposits. 


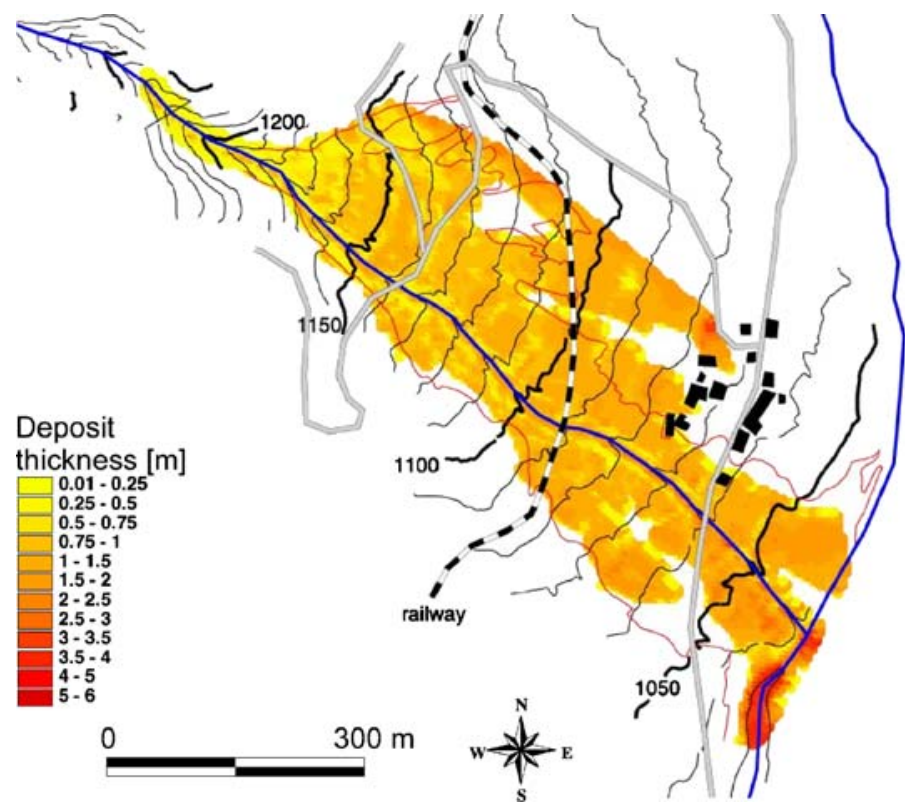

Figure 2. Simulated deposition depths for the Varunasch debris-flow event with the FLO-2D ${ }^{\circledR}$ model. The simulation is based on: peak discharge $Q_{\mathrm{p}}=600 \mathrm{~m}^{3} \mathrm{~s}^{-1}$, event volume $V=216,000 \mathrm{~m}^{3}$, friction parameters $n=0.16 \mathrm{sm}^{-1 / 3}, \mu_{\mathrm{B}}=1,000 \mathrm{~Pa}$ s and $\tau_{\mathrm{B}}=3,500 \mathrm{~Pa}$. The (red) outline represents the limit of deposition observed in the field.

The model results are sensitive to peak discharge: a 50\% higher discharge than used in the first simulation results in a different lateral spreading of the deposits (figure 1b). This simulation produces much larger (lateral) deposits in the northeastern part near the fan apex. A possible explanation is an increase in flow height near the fan apex, which results in an overtopping of some natural field barriers. This effect appears to depend on the site-specific field topography. Consequently, less material reaches areas further downstream, where smaller lateral spreading near the channel and in generally smaller deposit heights are simulated.

\subsection{Simulations with FLO-2D model}

Since no independent estimates of the model friction parameters are available, they were systematically and incrementally adjusted until good agreement between the simulated and observed deposition pattern was obtained. For the laminar flow resistance parameter for overland flow, $K_{1}$, a value of 24 is used, in agreement with the integration of the Bingham equation [36]. In the FLO-2D ${ }^{\circledR}$ manual [9], a higher value of $K_{l}=2,285$ is recommended for a rough surface of an alluvial fan (based on observations with Newtonian fluids). The selection of a higher $K_{1}$ value would not affect our simulations, but would simply result in lower back-calculated viscosity 


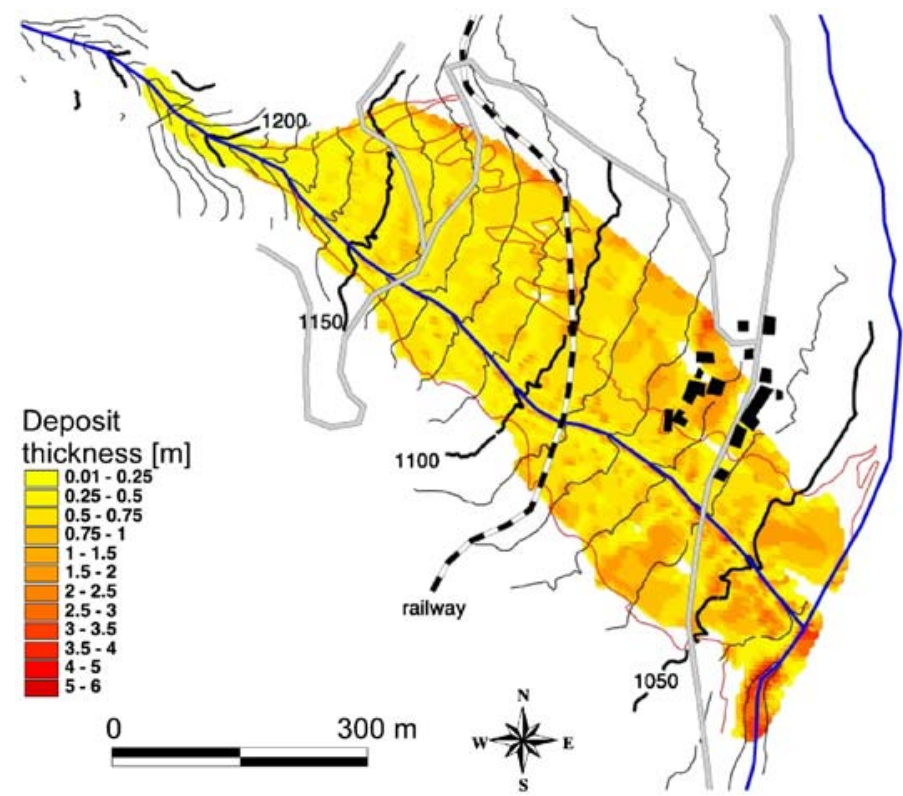

Figure 3. Simulated deposition depths for the Varunasch debris-flow event with the FLO-2D ${ }^{\circledR}$ model. The simulation is based on the same parameters as in figure 2, except for the yield stress, which is $\tau_{\mathrm{B}}=2,000$ $\mathrm{Pa}$. The (red) outline represents the limit of deposition observed in the field.

Table 1

Influence of $\tau_{\mathrm{c}} / \rho$ value on the area of the surface covered by deposits.

\begin{tabular}{llllllrrr}
\hline Torrent & \multicolumn{3}{c}{ Wartschenbach } & \multicolumn{5}{c}{ Varunasch } \\
\hline$\tau_{\mathrm{c}} / \rho$ value $\left(\mathrm{m}^{2} \mathrm{~s}^{-2}\right)$ & 0.8 & 0.9 & 1.0 & 1.1 & 1.35 & 1.45 & 1.8 & 2.2 \\
Mud-covered area (ha) & 1.76 & 1.71 & 1.60 & 1.50 & 1.28 & 15.2 & 15.0 & 13.2 \\
\hline
\end{tabular}

values. (This is a consequence of our procedure to optimize the model parameter to obtain best agreement with the field observations.)

The model parameters are varied as follows: pseudo-Manning value $(n)$ between 0.1 and $0.16 \mathrm{~s} / \mathrm{m}^{1 / 3}$, dynamic viscosity $\left(\mu_{\mathrm{B}}\right)$ between 0.001 and $10,000 \mathrm{~Pa}$ s and yield stress $\left(\tau_{\mathrm{B}}\right)$ between 0.001 and 5,000 Pa. These values approximately encompass published data. A fixed sediment concentration of $50 \%$ is assumed in order to have constant Bingham parameters for the each simulation. To optimize the model parameters, the following criteria are used: (i) final extent of the debris flow deposits, (ii) final accumulation depth of the deposits, (iii) velocity and height of the debris flow front along the torrent channel (rough estimates by observers).

A reasonable agreement of the maximum depositional extent can be obtained for the friction parameters $n=0.16 \mathrm{sm}^{-1 / 3}, \mu_{\mathrm{B}}=1,000 \mathrm{~Pa} \mathrm{~s}$ and $\tau_{\mathrm{B}}=3,500 \mathrm{~Pa}$ (figure 2). 
Modelled overbank deposit thicknesses are less than $2 \mathrm{~m}$ in most areas, in general agreement with observed values. The southernmost deposits (at the downstream end of the fan) show the largest simulated thicknesses of up to $6 \mathrm{~m}$. This is in qualitative agreement with field observations, although the absolute maximum values are higher in reality. Compared to field observations, the model results lack some lateral deposits in the downstream part. Also, in the upper left-hand side of the fan, debris material flows too far downstream in a southeast direction. About $15 \%$ of the input volume flows out of the modelling domain.

Figure 3 illustrates the effect of using a smaller yield stress value $\tau_{\mathrm{B}}$ of $2,000 \mathrm{~Pa}$ but otherwise the same parameters and input conditions (as in figure 2). This simulation reflects a more "liquid" flow, resulting in shallower deposits and somewhat more lateral spreading. More importantly, about $92,000 \mathrm{~m}^{3}$ or $43 \%$ of the input volume flows out of the modelling domain. Therefore the average deposit thickness is too small in comparison to the observations.

The relative importance of the three components of the friction slope equations ( $2 \mathrm{a}$ and $2 \mathrm{~b}$ ) on the flow was examined for a location in the channel and one on the fan outside of the channel. The results show that the influence of the viscosity term on the flow behaviour starts to become important for $\mu_{\mathrm{B}}$ values between 1,000 and 10,000 $\mathrm{Pa}$ $\mathrm{s}$. Moreover, the $n$-term is much more significant for the location in the torrent channel where velocities are clearly larger than anywhere else on the fan.

The simulation results best approximate the data observed in the field when applying a Manning value $n=0.16 \mathrm{~s} / \mathrm{m}^{1 / 3}$ (smaller $n$ values give too fast flow velocities). A series of simulations varying the friction parameters in the ranges given above showed that the dynamic viscosity does not significantly affect the results even for very large $\mu_{\mathrm{B}}$ values of up to $10,000 \mathrm{~Pa} \mathrm{~s}$. The dominant terms in the friction relations (2a) and (2b) over most of the fan area are the pseudo-Manning term and the yield stress, whereas realistic values of the dynamic viscosity have no significant influence on the flow behaviour or the extent of the deposition on the fan. Assuming an average mixture density of $2,000 \mathrm{~kg} / \mathrm{m}^{3}$, the optimal yield stress $\tau_{\mathrm{B}}=3,500 \mathrm{~Pa}$ correspond to a $\tau_{\mathrm{B}} / \rho$ ratio $=1.75 \mathrm{~m}^{2} \mathrm{~s}^{-2}$, which is close to the ratio of $\tau_{\mathrm{c}} / \rho=1.8 \mathrm{~m}^{2}$ $\mathrm{s}^{-2}$ used in the HB simulations.

\section{Application to a mud flow event in the Wartschenbach torrent}

The Wartschenbach catchment is located near Lienz, Eastern Tyrol, Austria. The catchment area is $2.5 \mathrm{~km}^{2}$, the altitude ranges from 2,500 to $650 \mathrm{~m}$ a.s.1., the mean gradient of the fan is $16 \%$, and a channel is present within the spreading and depositional zone on the fan with a mean gradient of 5\%. The debris flow event occurred on 16 August 1997 after an intense rainfall with hail (40 mm within $20 \mathrm{~min}$ ). About $45,000 \mathrm{~m}^{3}$ of water and sediments were mobilized within $30 \mathrm{~min}$ and reached a debris retention basin at the apex of the alluvial fan. Half of the debris-flow material was deposited there, the remaining 20,000-25,000 $\mathrm{m}^{3}$ of material flowed 
further downstream and spread on the alluvial fan where 15 buildings were damaged [14].

Lacking more precise information, two cases are considered regarding the triangular shaped input hydrograph for the simulations downstream of the retention basin: For the basic simulation a peak discharge of $100 \mathrm{~m}^{3} / \mathrm{s}$ is estimated from empirical relationships for a total volume $25,000 \mathrm{~m}^{3}$ [37], and for the sensitivity calculations with the HB model a peak discharge of $16 \mathrm{~m}^{3} / \mathrm{s}$ is deduced from hydrological considerations (based on the observed rainfall and using a rainfall-runoff model).

The centre of deposition is at the upstream end of the settlement, with deposit thicknesses ranging from 2.5 to $4 \mathrm{~m}$ (figure 4 ) in an elongated lobe centred along the channel. Over the remainder of the deposit the thickness was less than $2.5 \mathrm{~m}$. The plan view of the deposit shows one main lobe situated on the left side of the channel consisting of the coarsest sediment, and another lobe further downstream on the right side consisting of finer particles (cobbles, gravel and smaller particles).

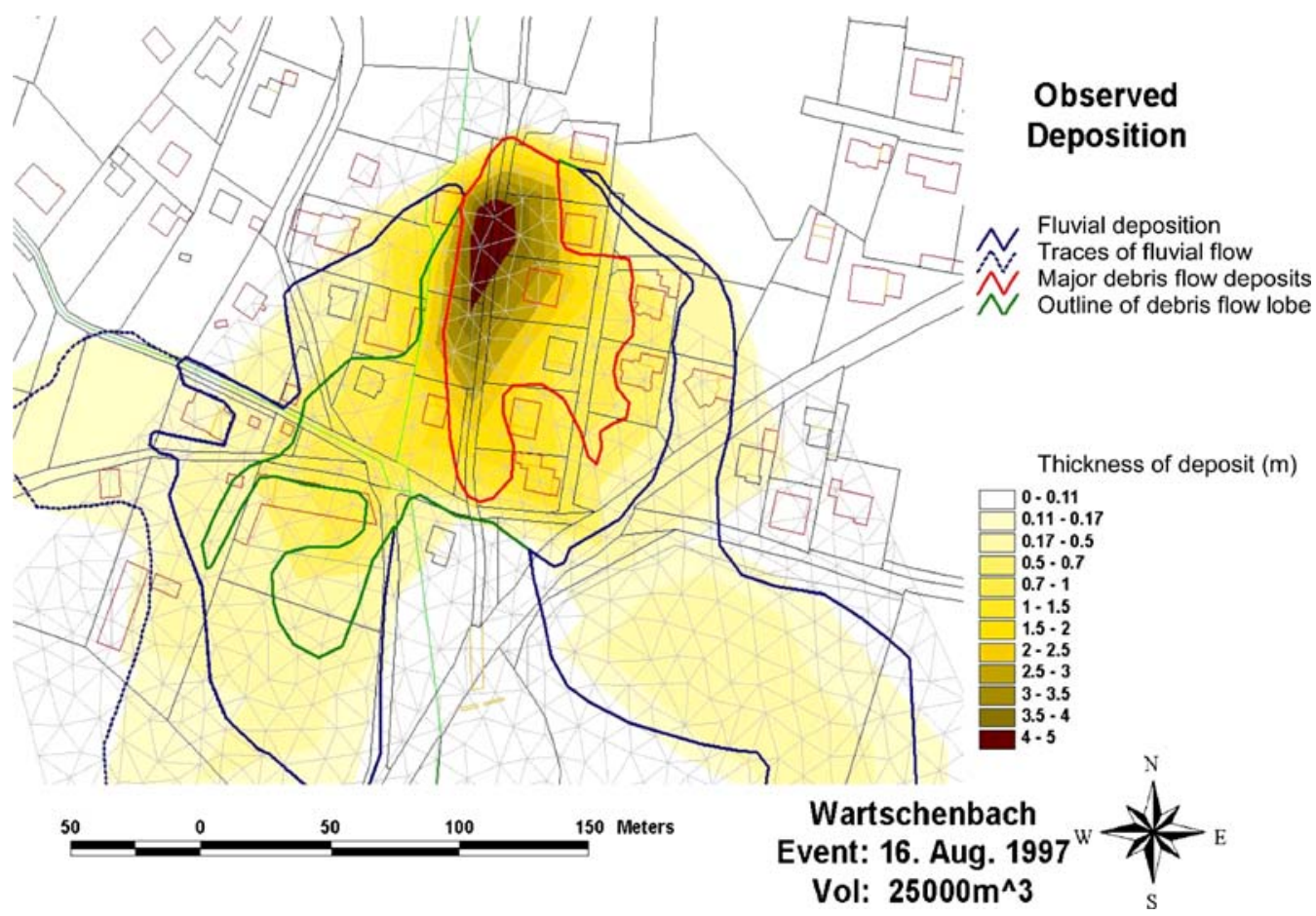

Figure 4. Observed deposition depth for the Wartschenbach debris-flow event of 16 August 1997. The inner (red) outline encloses the coarsest deposits, the middle (green) line encompasses the boundary of the debris flow deposits, the outer (blue) line encloses the fine deposits resulting from fluvial reworking, and the boundary delineated by the yellow color (outer blue line) corresponds to the overall flooded area. 


\subsection{Simulations with the $H B$ model}

Before running the model, the values of the rheologic parameters were independently characterized in the laboratory using conveyor-belt flume tests [15] on the fraction smaller than $2 \mathrm{~cm}$. For a solid volume concentration of 55-60\%, the yield stress $\tau_{\mathrm{B}}$ for the fine fraction was estimated at 53-79 $\mathrm{Pa}$ and the Bingham viscosity $\mu_{\mathrm{B}}$ at $4.0-6.3 \mathrm{~Pa} \mathrm{~s}$ [14]. It is not possible to deduce the yield stress value of the material including the complete grain size distribution from these observations. However, the behaviour of this fine fraction is clearly viscoplastic and could be represented by a Bingham or Herschel-Bulkley model. Furthermore, the shape of the lobes in the field is consistent with viscoplastic behaviour. Consequently, the Herschel-Bulkley model is assumed to be valid. The yield-stress value $\left(\tau_{\mathrm{c}} / \rho\right)$ is deduced from photographs taken shortly after the event. Thus information coming from a small part of the deposit is used to represent the yield stress of the entire flow. Based on deposit thickness and local slope at that point, values of $\tau_{\mathrm{c}} / \rho$ ranging from 0.8 to $1.35 \mathrm{~m}^{2} \mathrm{~s}^{-2}$ are estimated, using the relationship $\tau_{\mathrm{c}} / \rho=g d \sin \beta$ (with $d=$ deposit thickness, $\beta=$ deposit slope). The $K / \tau_{\mathrm{c}}$ ratio is taken equal to $0.3 \mathrm{~s}^{1 / 3}$, corresponding to a mean value proposed by Coussot et al. [6] on the basis of previous field investigations.

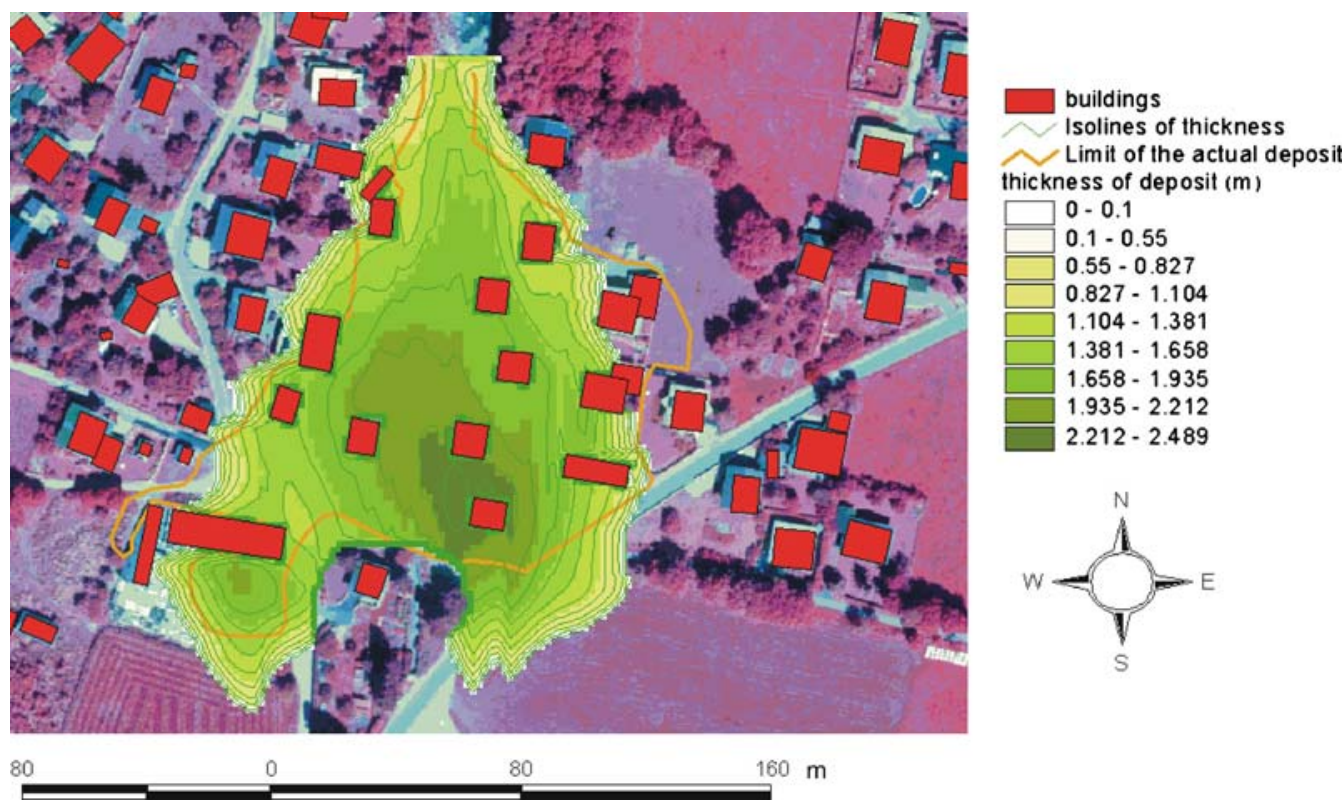

Figure 5. Simulated deposition depths of the Wartschenbach debris-flow event with the HB model. The simulation is based on: peak discharge $Q_{\mathrm{p}}=100 \mathrm{~m}^{3} \mathrm{~s}^{-1}$, event volume $V=25,000 \mathrm{~m}^{3}$, Herschel-Bulkely parameters $\tau_{\mathrm{c}} / \rho=1.0 \mathrm{~m}^{2} \mathrm{~s}^{-2}$ and $K / \tau_{\mathrm{c}}=0.3 \mathrm{~s}^{1 / 3}$. The (orange) outline encompasses the boundary of the observed debris flow deposits. 
The first simulation is based on a peak input discharge of $100 \mathrm{~m}^{3} / \mathrm{s}$. A grid of $2-\mathrm{m}$ square cells, corresponding to the zone of spreading, is used. Houses as well as a partly forested area upstream of the main village were treated as obstacles. The global shape of the deposit extent is reasonably well simulated for $\tau_{\mathrm{c}} / \rho=1.0 \mathrm{~m}^{2} \mathrm{~s}^{-2}$ and $K / \tau_{\mathrm{c}}=$ $0.3 \mathrm{~s}^{1 / 3}$ (figure 5), values selected from within the range discussed above. The model deposits are somewhat thicker on the left side of the channel, yet approximately evenly distributed on both sides. The area of maximum of deposition is about $90 \mathrm{~m}$ downstream of the maximum of the coarse deposit lobe observed in the field. The width of the lobe is quite similar to that observed for the main coarse lobe in the real deposit. At the downstream end the model, results show two sub-equal sized depositional lobes, whereas in the field the right lobe is more prominent (figure 5). Even though the simulation does not perfectly agree with the delineation of real event (there is some discrepancy particularly at the eastern and southeastern part), the area covered by coarse debris-flow deposits is similar for the simulation and reality.

Variations of the peak discharge do not seem to highly influence the spreading extent for the Wartschenbach event. In fact, a simulation with a peak input discharge of $16 \mathrm{~m}^{3} / \mathrm{s}$ and the same rheologic parameters as above, produces a very similar deposition pattern (figure 6).

An independent assessment of rheologic parameters values corresponding to the flowing material is difficult. For example, relative uncertainty related to the $\tau_{\mathrm{c}} / \rho$ ratio is often greater than $20 \%$. The sensitivity to variations of $\tau_{\mathrm{c}} / \rho$ is larger than the

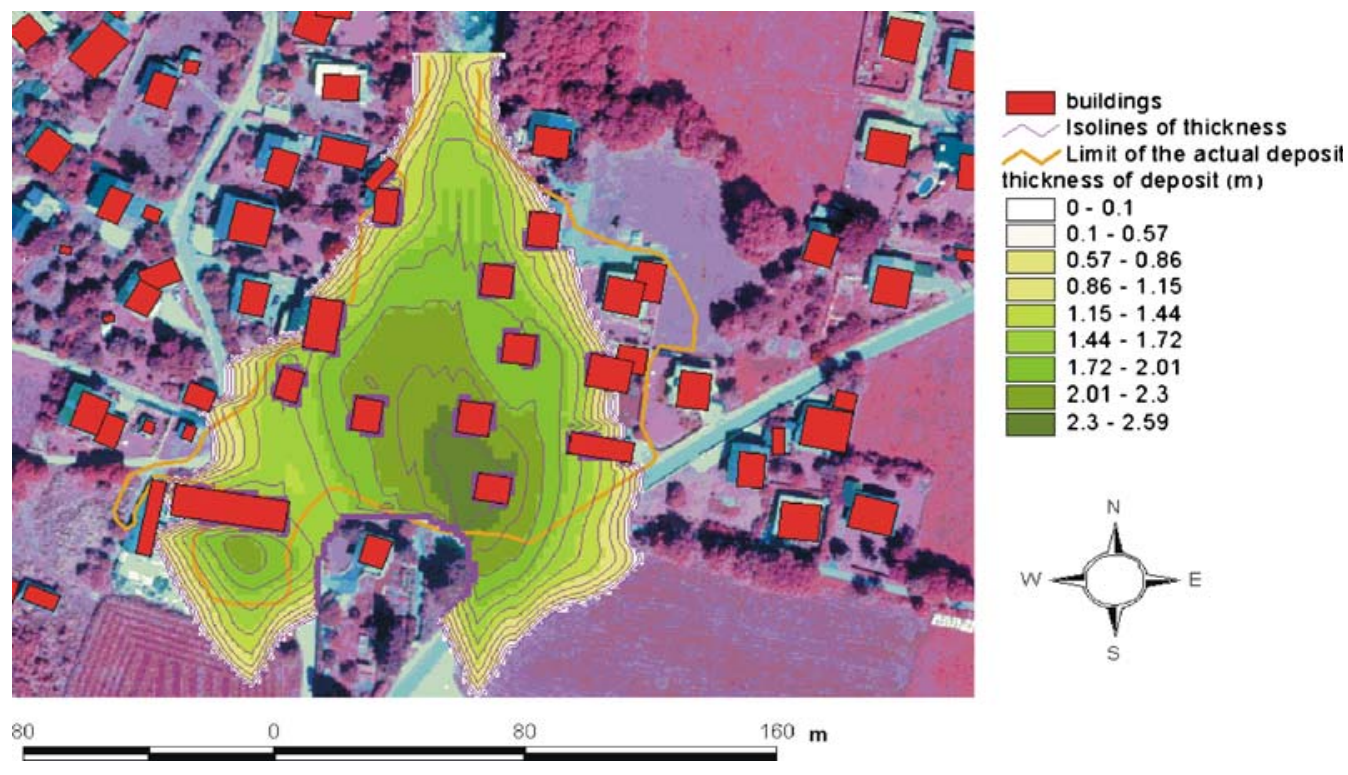

Figure 6. Simulated deposition depths of the Wartschenbach debris-flow event with the HB model. The simulation is based on the same parameters as for figure 5, except for the peak discharge, $Q_{\mathrm{p}}=16 \mathrm{~m}^{3} \mathrm{~s}^{-1}$. 
sensitivity to variations of $K / \tau_{\mathrm{c}}$. For the Wartschenbach (using a peak discharge of 16 $\mathrm{m}^{3} / \mathrm{s}$ ), a variation of $10 \%$ in $\tau_{\mathrm{c}} / \rho$ leads to a mean change of $6.5 \%$ in the area covered by the deposits (table 1), while a variation of $33 \%$ in the $K / \tau_{\mathrm{c}}$ ratio has only a small effect.

Several grids consisting of $5 \mathrm{~m}$ (generated with or without the use of break lines) or $2 \mathrm{~m}$ square cells corresponding to the zone of spreading were used to investigate the influence of the representation of topography on the results. Most simulations used the 2-m grid; the 5-m grids were used for the sensitivity analysis. The quality of the simulations is clearly better when using the finer grid (small-sized cells). The $2 \mathrm{~m}$ grid also better represents the influences of man-made structures on the results. The appropriate method to generate a grid on the basis of the net of surveyed points, involved generating triangular irregular network (TIN) first rather than directly generating the grid. The representation of the field surface in a TIN can also be improved by integrating break-lines representing roads, channels or edges.

\subsection{Simulations with the DFEM-2D model}

For application to the Wartschenbach torrent, the DFEM-2D model is run using the Voellmy fluid friction law. It is not possible to independently constrain the model friction parameters of the Voellmy fluid approach, necessitating a systematic, incremental adjustment of the parameters to find good agreement between the simulated and observed deposition pattern. A grid consisting of 1,576 elements, with an average area of about $50 \mathrm{~m}^{2}$, was constructed to represent both the topography and the outlines of buildings and other structures. Other grid resolutions were tested in an initial step; however, the results were roughly similar and the selected mesh geometry represents a good combination of topographic accuracy and computational speed. Because the boundaries of the elements can follow topographic break lines, it is possible to use such relatively large elements and still obtain realistic results.

Given the complexity of the observed deposition, it was possible to reasonably well match the overall deposition pattern with several pairs of friction values for the Voellmy fluid approach. The best match was found for the following parameter combinations: $C=11 \mathrm{~m}^{0.5} / \mathrm{s}$ and $\delta=3-5^{\circ}$ (figures 7 and 8 ). A sensitivity study was made using the Voellmy friction relation with a constant $C=11 \mathrm{~m}^{0.5} / \mathrm{s}$ and varying the Coulomb friction angle $\delta$ between $7^{\circ}$ and $0.4^{\circ}$. Relatively large friction angles (e.g., $5^{\circ}$ or $7^{\circ}$ ) more closely match the depositional area of the (coarser) debris-flow deposits, while small values (e.g., $0.4^{\circ}$ ) more closely match the outline of the area inundated by fine sediments and muddy water.

The best-fit DFEM-2D model deposits are approximately evenly distributed on both sides of the channel, with the centre of deposition near the downstream end of the coarse deposit lobe observed in the field. The area of maximum deposition is about 70 $\mathrm{m}$ downstream of that observed in the field; however, the width of the model deposit is similar to the width of the observed coarse lobe. Downstream of the main deposit, the 


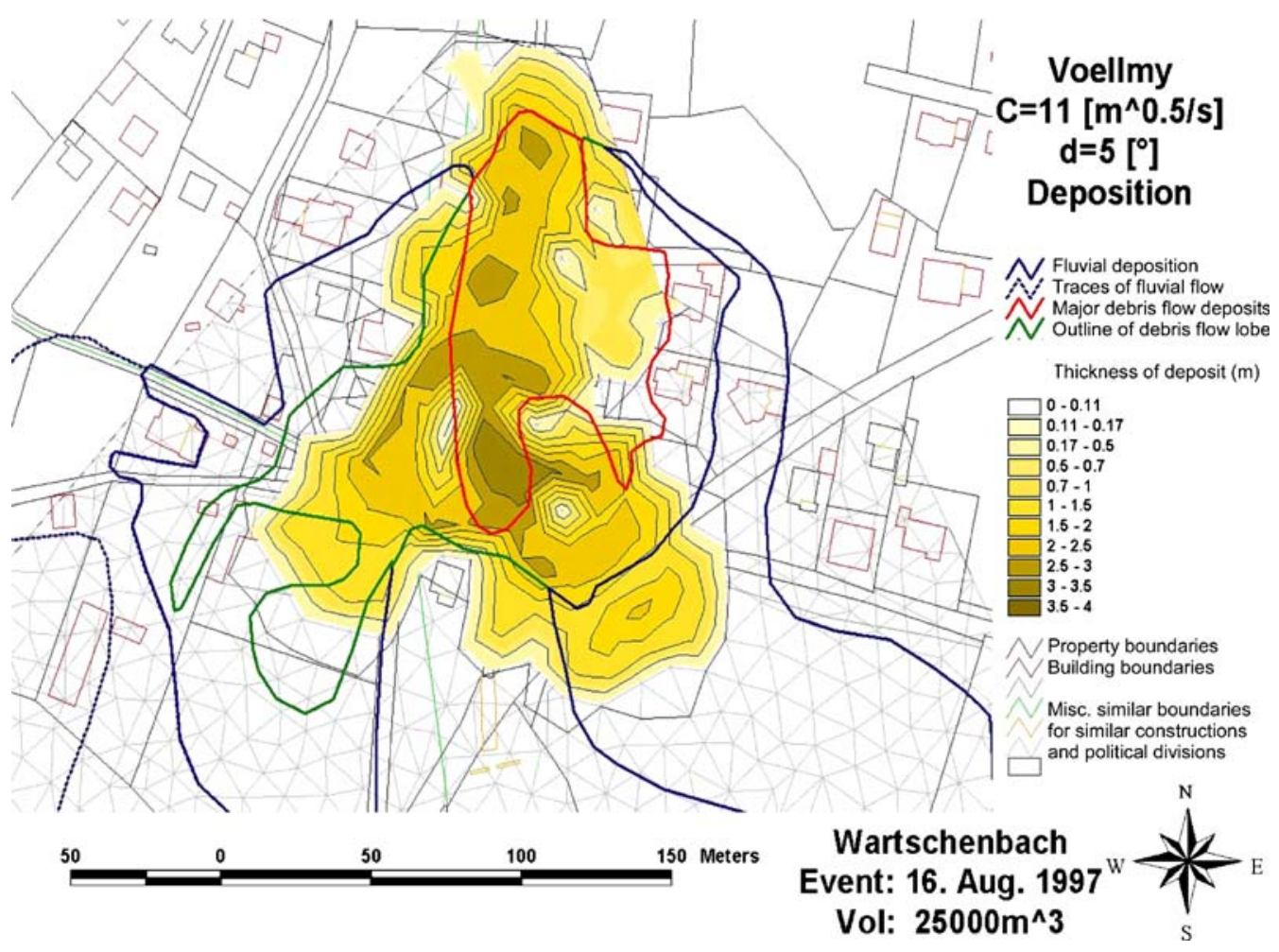

Figure 7. Simulated deposition depths of the Wartschenbach debris-flow event with the DFEM-2D model for a Voellmy fluid. The simulation is based on: peak discharge $Q_{\mathrm{p}}=100 \mathrm{~m}^{3} \mathrm{~s}^{-1}$, event volume $V=$ $25,000 \mathrm{~m}^{3}$, Voellmy parameters $C=11 \mathrm{~m}^{0.5} / \mathrm{s}$ and $\delta=5^{\circ}$. For explanation of the observed deposition outlines, see figure 4 .

model deposits consist of two sub-equal sized lobes, whereas in the field the right lobe is more prominent. Apart from the difference in the location of the maximum deposit height, the model results show deposit thicknesses similar to those observed in the field.

The importance of accurate topographic data on the fan, including, for example, representation of man-made constructions, was investigated for the Voellmy fluid approach. The simulated deposition pattern including more topographic information, such as houses and retaining walls of similar height as the flow depth, clearly improved the agreement with field observations [42].

\section{Discussion}

Uncertainties in estimating debris flow properties for modelling include errors in estimating peak discharge, hydrograph shape, total event volume, as well as rheologic 


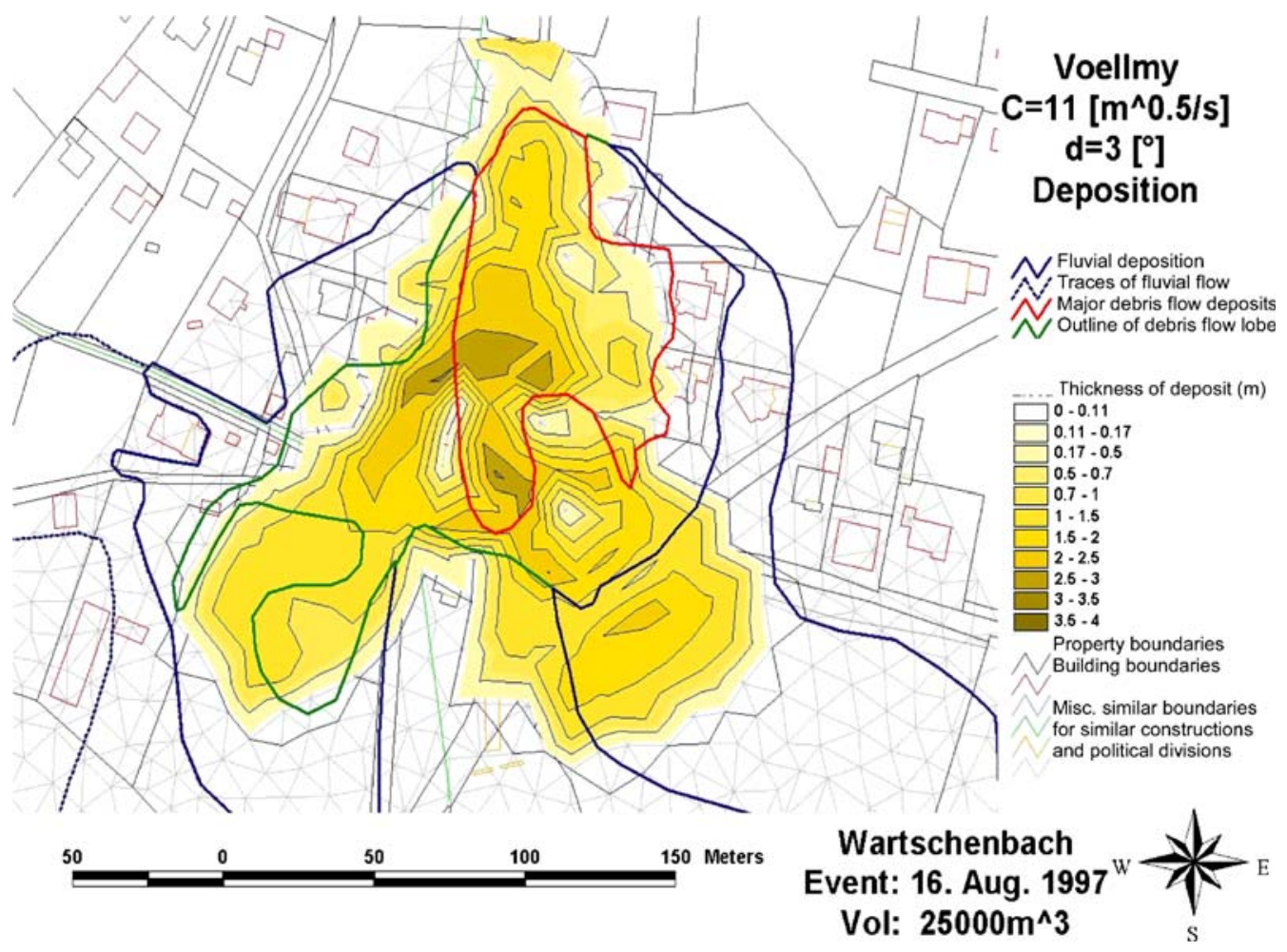

Figure 8. Simulated deposition depths of the Wartschenbach debris-flow event with the DFEM-2D model for a Voellmy fluid. The simulation is based on the same parameters as for figure 7, except for the basal friction angle which is $\delta=3^{\circ}$. For explanation of the observed deposition outlines, see figure 4 .

or friction parameters. Estimating peak discharge is complicated because the velocity profile is generally unknown and only surface velocity estimates are available; but occasionally it is possible to constrain the discharge from derived mud trace, channel cross-sectional area and planform curvature. Total event volumes of past events can be constrained by field surveys of the deposit volume or initial failure volume, but these estimates often do not include material entrained or deposited along the flow path or the proportion of material that may have been transported from the depositional area by, e.g., a river at the toe of the alluvial fan. For practical predictive model applications, such problems are circumvented by running the simulation model with various reasonable scenarios for volume, peak discharge, and friction parameters.

A simplification is the use of a single surge input hydrograph, e.g., for the multisurge Varunasch event. Simulation with a multi-surge input hydrograph may lead to different results, for example, if a smaller surge stops at a critical location inducing a flow diversion of successive surges. Such a simulation would require updating the bed topography, which is not an option in any of the models applied herein. Furthermore, 
assumptions would have to be made about the magnitude, frequency, and frictional properties of the different surges as well as the erosional response of the material deposited from earlier surges.

Any of the models we used is suitable for modelling debris-flow deposition, after calibration with historical data, suggesting that the models captured the salient features of the stopping process. While it may be possible to determine which model is most appropriate with additional velocity information, such field data are seldom available. Because the runout and final deposition depths are reasonably reproduced, it is likely that the simulated velocities during the final stage are not too different from real values.

We assumed that the friction coefficients remained constant over the duration of the event. More sophisticated approaches are available, for example, an empirical relation between rheologic parameters and sediment concentration [34]. We did not use these approaches to avoid introducing additional unknowns that cannot be reasonably constrained with the field data.

Accurate representation of the topography is critical. In many debris flows, the roughness height is large compared with the flow depth, so small errors in the representation of the topography may change the local flow and the resulting depositional pattern. More detailed spatial resolution of the channel and fan topography strongly improves the model results in many cases. Incorporation of the effect of flow obstructions by buildings and other constructions is also helpful. Irregular triangular meshes, as in the DFEM-2D model, can be constructed to exactly represent such structures. Representation of any pre-existing channels is also critical. If the input conditions are changed, e.g., by selecting a larger peak discharge, the flow may go overbank in a different location and substantially influence the deposition pattern as well, as with the Varunasch case.

Based on the experience in comparing 1D simulations with field cases $[30,31,42]$, the Voellmy fluid approach is numerically stable in comparison with other friction relations. Back-calculated Voellmy parameters are consistent between the $1 \mathrm{D}$ and the $2 \mathrm{D}$ simulations. The Chezy $C$ value varies from about 7 to $22 \mathrm{~m}^{1 / 2} / \mathrm{s}$, consistent with friction values for water flows in similar channels and in agreement with back-calculated values for a large number of channelized debris flow observations [37]. In applications of the Voellmy relation with a mass-point model to debris flows, the Coulomb friction angle $\delta$ tends to be approximately equal to the slope of the fan at the stopping location [38]. However, the best-fit friction angle in the Wartschenbach case is about $\delta=5^{\circ}$, somewhat larger than the fan slope of the depositional zone. Similar best-fit values for $\delta$ were obtained in other continuum model applications to debris flows $[1,35]$.

The application of the quadratic friction law $\left(\mathrm{FLO}-2 \mathrm{D}^{\circledR}\right.$ model) requires estimates of several friction parameters. Back-calculated pseudo-Manning $n$ values vary in a limited range $n=0.07-0.16 \mathrm{~s} / \mathrm{m}^{1 / 3}$ [42], in agreement with back-calculated values for a large number of channelized debris flow observations [40]. For the 
Varunasch torrent with a rather steep fan gradient $(\sim 15 \%)$, the Manning and yield stress terms are dominant. This agrees with a similar detailed analysis of the relative importance of the three friction terms for other field cases [42]: for a point in the channel where the velocity is large, the turbulent friction term dominates. As the velocity decreases, e.g., near the stopping zone, its influence decreases and the yield stress term, which largely controls runout and lateral spreading, becomes increasingly important. The laminar friction term, which may influence the lateral spreading of the deposits, remained small and did not significantly influence the results. Simulations with a realistic range of dynamic viscosity values did not significantly influence the flow behaviour or the extent of deposition. The assumed yield stress and viscosity used in this study may be outside the range of values for which the FLO-2D ${ }^{\circledR}$ was developed and calibrated; the model may replicate the field conditions more closely if yield stress and viscosity were allowed to vary as a function of sediment concentration.

In the Herschel-Bulkley modelling approach, the viscosity $K$ basically replaces the role of Chezy $C$ and Manning $n$ in the "turbulent"-based Voellmy and quadratic models. The yield stress generally dominates the frictional behaviour in the depositional phase. However, from 1D simulations it was found that the Bingham approach, which as mentioned earlier is a special case of the Herschel-Bulkley approach, results in unrealistically large velocity changes along the flow path for some channelized flows (if the stopping location is correctly matched by calibration of the friction parameters). Coussot's method of estimating of the yield-stress value [6], applied to the Moscardo debris flow torrent in Italy (fan slope of $10.5 \%$ ), produced a yield stress of about $3,000 \mathrm{~Pa}$. With an assumed density of about $2,000 \mathrm{~kg} / \mathrm{m}^{3}$, the $\tau_{\mathrm{c}} / \rho$ ratio is $1.5 \mathrm{~m}^{2} \mathrm{~s}^{-2}$. These values are similar to those used in the FLO-2D ${ }^{\mathbb{R}}$ and HB simulations in this study. Other applications of the HB model resulted in values usually between 1.0 and 2.0 for spreading flows. In some recent applications of the 1D version of the HB model to flow in channels, an additional turbulent friction term was found to improve simulation results.

It was not possible to directly compare the numerical schemes among the models because they do not have a common rheological relation, and the numerical scheme is fixed in each program. A comparison of the Voellmy rheology using the 1D version of the DFEM simulation code and a finite volume simulation with another code show similar results for the two numerical schemes for mean flow depth and mean flow velocity [46], suggesting that the results may not strongly depend on the numerical solution. The HB model was found to be in good agreement with controlled experimental conditions [25], thus confirming the validity of the numerical scheme.

These modelling approaches all suffer from a need for calibration with historical data; in principle, a more physically based model with fewer adjustable parameters would be preferable. Ideally, this approach would require material parameters that can be determined, for example, by analysing soil samples. However, such models are not yet generally available and at any rate their validation in the field scale will involve 
comparison with well-documented field observations of the flow and depositional behaviour. Until such models have been thoroughly tested, modelling approaches, as described herein, will remain in common use for practical problems.

\section{Conclusions}

Three 2D debris-flow simulation models were applied to two well-documented field events. The following event parameters were used to perform the simulations and to assess the results: (i) total event volume, (ii) peak discharge, and (iii) extent and thickness of debris-flow deposits on the fan. Criteria (i) and (iii) are known quite accurately. The peak discharge is indirectly constrained by other observations for the Varunasch event; no similar estimate is available for the Wartschenbach event. Reasonable results for the extent of deposits and the relative spatial distribution of deposit thicknesses could be achieved with all three models.

Accurate representation of the topography in the grid is essential to obtain a reasonable replication of the observed deposition patterns. A more detailed spatial resolution of the channel and fan topography strongly improves the model results in many cases. Results also improve if the effect of flow obstructions such as buildings is incorporated into the model. If the input conditions are changed, e.g., by selecting a higher peak discharge, the interaction of the flow and the topography, e.g., the generation of overbank flow at cross-sections where the flow area is relatively low, can significantly influence the results.

Possible explanations for the inaccuracy of the model results include both systematic topographic errors or the simplification of the real multi-surge event by a single triangular hydrograph. Bed level changes either between successive surges or at the base of a flow within one surge may cause a local change in the direction of the flow.

Because simulation models often require calibration, a major drawback in view of engineering applications is that most of these models have not been rigorously tested against field events. Nevertheless, some general characteristics of debris flow deposits, which are necessary for hazard assessment, may be reasonably well simulated with these simple modelling approaches if rheologic or friction parameters can be measured or calibrated (ideally, by replicating past events in the same torrent). In all the tested model applications, the yield stress or the basal friction angle appeared to govern the depositional behaviour to a large extent.

\section{Acknowledgements}

We would like to thank Christoph Graf, Marcel Huerlimann, Daniel Naef, and Anne-Francoise Hector for the support with data preparation and simulation 
calculations. The study has been supported by the project "Torrent Hazard Control in the European Alps. Practical Tools and Methodologies for Hazard Assessment and Risk Mitigation." - THARMIT (EVG1-CT-1999-00012) funded by the European Commission. We thank the reviewers for constructive comments which helped to improve the manuscript.

\section{References}

[1] D. Ayotte and O. Hungr, Calibration of a runout prediction model for debris-flows and avalanches, in: Debris-Flow Hazards Mitigation: Mechanics, Prediction, and Assessment, Proc. 2nd International DFHM Conference, eds. G.F. Wieczorek and N.D. Naeser (2000) (Taipei, Taiwan, 2000) pp. 505-514.

[2] P. Brufau, P. Garcia-Navarro, P. Ghilardi, L. Natale and F. Savi, 1D mathematical modelling of debris flow, J. Hydraul. Res. 38(6) (2000) 435-446.

[3] H. Chen and C.F. Lee, A dynamic model for rainfall-induced landslides on natural slopes, Geomorphology 51(4) (2003) 269-288.

[4] M.H. Chuang, T.J. Chang, M.H. Hsu and M.L. Lin, An analysis of debris-flow transport in tributaries of Chen-Yo-Lan Creek, Taiwan, in: Debris-Flow Hazards Mitigation: Mechanics, Prediction, and Assessment, Proceedings 2nd International DFHM Conference, eds. G.F. Wieczorek and N.D. Naeser (2000) (Taipei, Taiwan, 2000) pp. 515-519.

[5] P. Coussot, Steady, laminar flow of concentrated mud suspensions in open channel, J. Hydraul. Res. 32(4) (1994) 535-559.

[6] P. Coussot, D. Laigle, M. Arattano, A. Deganutti and L. Marchi, Direct determination of rheological characteristics of debris flow, J. Hydraul. Eng. 124(8) (1998) 865-868.

[7] G.B. Crosta, H. Chen and C.F. Lee, Replay of the 1987 Val Pola Landslide, Italian Alps, Geomorphology 60(1-2) (2004) 127-146.

[8] R.P. Denlinger and R.M. Iverson, Flow of variably fluidized granular masses across threedimensional terrain. 2. Numerical predictions and experimental tests, J. Geophys. Res. 106(B1) (2001) 537-552.

[9] FLO-2D, Users' Manual, Version 99.2 (FLO Engineering Inc., Nutrioso, Arizona, USA, September 1999).

[10] L. Fraccarollo and M. Papa, Numerical simulation of real debris-flow events, Phys. Chem. Earth, Part B 25(9) (2000) 757-763.

[11] R. García, J.L. López M. Noya, M.E. Bello, M.T. Bello, N. González, G. Paredes, M.I. Vivas and J.S. O'Brien, Hazard mapping for debris flow events in the alluvial fans of northern Venezuela, in: Debris-Flow Hazards Mitigation: Mechanics, Prediction, and Assessment, Proc. of 3rd International DFHM Conference, eds. D. Rickenmann and C.L. Chen (2003) (Davos, Switzerland, 2003) pp. 589-599.

[12] P. Ghilardi, L. Natale and F. Savi, Debris-flow propagation on urbanized alluvial fans, in: DebrisFlow Hazards Mitigation: Mechanics, Prediction, and Assessment, Proc. 2nd International DFHM Conference, eds. G.F. Wieczorek and N.D. Naeser (2000) (Taipei, Taiwan, 2000) pp. 471-477.

[13] G. Han and D. Wang, Numerical modeling of Anhui debris flow, J. Hydraul. Eng. 122(5) (1996) 262-265.

[14] J. Hübl and H. Steinwendtner, Zweidimensionale Modellierung von Murgängen anhand zweier ausgewählter Beispiele in Österreich, in: Proc. Internationales Symposium Interpraevent Villach, Oesterreich, 2000, Band 3, pp. 179-190 (in German). 
[15] J. Hübl and H. Steinwendtner, Estimation of rheological properties of viscous debris flows using a belt conveyor, Phys. Chem. Earth, Part B 25(9) (2000) 751-755.

[16] O. Hungr, A model for the runout analysis of rapid flow slides, debris flows, and avalanches, Can. Geotech. J. 32 (1995) 610-623.

[17] O. Hungr and S.G. Evans, A dynamic model for landslides with changing mass, in: Proc. Engineering geology and the environment, Athens, Greece (1997) pp. 719-724.

[18] M. Hürlimann, D. Rickenmann and C. Graf, Field and monitoring data of debris-flow events in the Swiss Alps, Can. Geotech. J. 40(1) (2003) 161-175.

[19] J. Imran, G. Parker, J. Locat and H. Lee, 1D Numerical model of muddy subaqueous and subaerial debris flows, J. Hydraul. Eng. 127(11) (2001) 959-967.

[20] R.M. Iverson, The physics of debris flows, Rev. Geophys. 35(3) (1997) 245-296.

[21] R.M. Iverson and R.P. Denlinger, Flow of variably fluidized granular masses across threedimensional terrain. 1. Coulomb mixture theory, J. Geophys. Res. 106(B1) (2001) 537-552.

[22] M. Jin and D.L. Fread, 1D modeling of mud/debris unsteady flows, J. Hydraul. Eng. 125(8) (1999) 827-834.

[23] P.Y. Julien and Y. Lan, Rheology of hyperconcentrations, J. Hydraul. Eng. 117(3) (1991) 346-353.

[24] N.D. Katopodes, Two-dimensional surges and shocks in open channels, J. Hydraul. Eng. 110(6) (1984) 794-812.

[25] D. Laigle, A two-dimensional model for the study of debris-flow spreading on a torrent debris fan, in: Debris-Flow Hazards Mitigation: Mechanics, Prediction, and Assessment, Proc. 1st International DFHM Conference, ed. C.L. Chen (1997) (San Francisco, CA, USA, 1997) pp. 123-132.

[26] D. Laigle and P. Coussot, Numerical Modeling of Mudflows, J. Hydraul. Eng. 123(7) (1997) 617-623.

[27] D. Laigle, A.-F. Hector, J. Hübl and D. Rickenmann, Comparison of numerical simulation of muddy debris flow spreading to records of real events, in: Debris-Flow Hazards Mitigation: Mechanics, Prediction, and Assessment, Proc. 3rd International DFHM Conference, eds. D. Rickenmann and C.L. Chen (2003) (Davos, Switzerland, 2003) pp. 635-646.

[28] G. Lorenzini and N. Mazza, Debris Flow: Phenomenology and Rheological Modelling (WIT Press, Southampton, UK, 2004) 202 pp.

[29] J.-P. Malet, O. Maquaire, J. Locat and A. Remaître, Assessing debris flow hazards associated with slow moving landslides: methodology and numerical analyses, Landslides 1(1) (2004) 83-90. DOI: 10.1007/s10346-003-0005-x.

[30] B.W. McArdell, B. Zanuttigh, A. Lamberti and D. Rickenmann, Systematic comparison of debris flow laws at the Illgraben torrent, Switzerland, in: Debris-Flow Hazards Mitigation: Mechanics, Prediction, and Assessment, Proc. 3rd International DFHM Conference, eds. D. Rickenmann and C.L. Chen (2003) (Davos, Switzerland, 2003) pp. 647-657.

[31] D. Naef, D. Rickenmann, P. Rutschmann and B.W. McArdell, Comparison of friction relations for debris flows using a one dimensional finite element simulation model, Natural Hazards and Earth System Sciences (in press).

[32] H. Nakagawa and T. Takahashi, Estimation of a debris flow hydrograph and hazard area, in: DebrisFlow Hazards Mitigation: Mechanics, Prediction, and Assessment, Proc. 1st International DFHM Conference, ed. C.L. Chen (1997) (San Francisco, CA, USA, 1997) pp. 64-73.

[33] H. Nakagawa, T. Takahashi and Y. Satofuka, A debris-flow disaster on the fan of the Harihara River, Japan, in: Debris-Flow Hazards Mitigation: Mechanics, Prediction, and Assessment, Proc. 2nd International DFHM Conference, eds. G.F. Wieczorek and N.D. Naeser (2000) (Taipei, Taiwan, 2000) pp. 193-201.

[34] J.S. O'Brien, P.Y. Julien and W.T. Fullerton, Two-dimensional water flood and mudflow simulation, J. Hydraul. Eng. 119(2) (1993) 244-261. 
[35] P. Revellino, O. Hungr, F.M. Guadagno and S.G. Evans, Velocity and runout simulation of destructive debris flows and debris avalanches in pyroclastic deposits, Campania region, Italy, Environ. Geol. 45(3) (2004) 295-311.

[36] D. Rickenmann, Bedload transport capacity of slurry flows at steep slopes, in: Mitteilung der Versuchsanstalt für Wasserbau, Hydrologie und Glaziologie, ETH Zürich 103 (1990), 249 pp.

[37] D. Rickenmann, Empirical relationships for debris flows, Nat. Hazards 19 (1999) 47-77.

[38] D. Rickenmann, Runout prediction methods, in: Debris-Flow Hazards and Related Phenomena, eds. M. Jakob and O. Hungr (Praxis-Springer, 2005) pp. 263-282.

[39] D. Rickenmann and T. Koch, Comparison of debris flow modelling approaches, in: Debris-Flow Hazards Mitigation: Mechanics, Prediction, and Assessment, Proc. 1st International DFHM Conference, ed. C.L. Chen (1997) (San Francisco, CA, USA, 1997) pp. 576-585.

[40] D. Rickenmann and D. Weber, Flow resistance of natural and experimental debris flows in torrent channels, in Debris-Flow Hazards Mitigation: Mechanics, Prediction, and Assessment, Proc. 2nd International DFHM Conference, eds. G.F. Wieczorek and N.D. Naeser (2000) (Taipei, Taiwan, 2000) pp. 245-254.

[41] D. Rickenmann and M. Zimmermann, The 1987 debris flows in Switzerland: documentation and analysis, Geomorphology 8(2-3) (1993) 175-189.

[42] D. Rickenmann, D. Laigle, A. Lamberti, B. Zanuttigh, A. Armanini, L. Fraccarollo, M. Giuliani, G. Rosati, B.W. McArdell, D. Naef, M. Swartz and C. Graf, Evaluation of existing numerical simulation models for debris flows, Report on work package 3 of the research project THARMIT of the European Union (2003), E.U. Contract EVG1-CT-1999-00012.

[43] P. Rutschmann, FE solver with 4D finite elements in space and time, in: Proc. VIII International Conference on Finite Elements in Fluids, Barcelona (1993) pp. 136-144.

[44] S.B. Savage and K. Hutter, The motion of a finite mass of granular material down a rough incline, J. Fluid Mech. 199 (1989) 177-215.

[45] C.L. Shieh, C.D. Jan and Y.F. Tsai, A numerical simulation of debris flow and its applications, Nat. Hazards 13 (1996) 39-54.

[46] M. Swartz, B.W. McArdell and P. Bartelt, Interpretation of the August 2000 Schipfenbach debris flow event using numerical models, Turbulenzen in der Geomorphologie, Mitteilung der Versuchsanstalt für Wasserbau, Hydrologie und Glaziologie, ETH Zürich, 184 (2004) pp. 51-60.

[47] T. Takahashi, Debris Flow (IAHR Monograph Series, Balkema, Rotterdam, The Netherlands, 1991), $165 \mathrm{pp}$.

[48] T. Takahashi, H. Nakagawa, T. Harada and Y. Yamashiki, Routing debris flows with particle segregation, J. Hydraul. Eng. 118(11) (1992) 1490-1507.

[49] B. Zanuttigh and A. Lamberti, Numerical modelling of debris surges based on shallow-water and homogeneous material approximations, J. Hydraul. Res. 42(4) (2004) 376-389. 